and smoking $(\beta=-0.26, P=0.01)$. These results confirm that, in nutritional management of gestational diabetes, carbohydrate intake has to be higher than $200 \mathrm{~g} /$ day and that fat intake must be restricted.

\section{Growth and nutrition of children of} Maghrebian origin living in Paris area. F Rovillé-Sausse (Laboratoire d'anthropologie biologique, Musée de l'Homme, place du Trocadéro, 75116 Paris, France).

Nutritional investigations made among the Maghrebian population living in France showed a progressive change in the habits, the traditional Mediterranean diet becoming more western, especially among young people. The purpose of this study was to evaluate the influence of the diet on the growth of children born in France, whose both parents immigrated from Maghreb.

- Method: In this longitudinal study, we enrolled 300 children from Maghrebian parents and 320 French children, under 6 years of age. They were regularly followed by paediatricians in the centres of 'Protection Maternelle et Infantile' (PMI) of the Parisian area. The successive biometric data (height, weight, etc) were collected in their medical files, from birth, each month during the first year, every 2 months during the second year, then every 6 months. About 15000 measurements were collected. The means of height, weight and body mass index (BMI) were computed for each age class. The BMI $\left(\mathrm{W} / \mathrm{H}^{2}\right)$ is a good index of the nutritional status of the children, and its dynamic analysis can predict a possible obesity.

- Results: At birth, no difference was observed in height, weight and BMI between both populations $(P>0.05)$. From the first weeks of life, the BMI means of children from Maghrebian immigrated parents were significantly higher $(P<0.01)$ than those of French children. At 1 year of age, 23\% of the Maghrebian BMI were greater than the percentile 90 for the reference French population. Of these obese Maghrebian children, $28 \%$ showed a precocious adiposity rebound between 30 and 36 months of age (reference value is about 72 months).

- Interpretation: These results point to the risk of obesity in children of Maghrebian parents living in Paris. They might be interpreted as a consequence of the change in diet habits. $77 \%$ of the Maghrebian newborns are exclusively breastfed at birth, but because an obese baby in this population is regarded as being in good health, mothers give readily cereals in addition of breastfeeding, which carries a faster growth of weight due to a supply of energy intake. When solid food is progressively introduced, many people think that 'westernalization' of food is a good sign of social integration, favourable to the health. In fact, they introduce nutritional imbalances: for example, a high intake of meat, a considerable supply of saturated fats (butter) takes the place of mono- and poly- insaturated fats (olive oil). The BMI growth of children of immigrated Maghrebian parents showed an evident overweight at each age, which could have an influence on precocious obesity and cardiovascular risks.

Tumor growth and oxidant-antioxidant status. M Gerber ${ }^{1}$, C Astre ${ }^{1}$, C Ségala ${ }^{1}$, M Saintot ${ }^{1}$, J Scali ${ }^{1}$, J Simonny-Lafontaine ${ }^{2}$, J Grenier ${ }^{2}$, H Pujol $^{2}\left({ }^{l}\right.$ Groupe d'épidémiologie métabolique; ${ }^{2}$ Centre anti-cancéreux, 34000 Montpellier, France).

Several lines of evidence suggest an alteration of the oxidant-antioxidant status in cancer. The biochemical analyses of experimental tumors show high levels of antioxidants and low levels of polyunsaturated fatty acids (PUFA) resulting in a low potential for lipid peroxidation. Such an alteration has been found in human cancer patients either in the plasma of breast cancer 